\title{
Self-Pressurization of a Flightweight, Liquid Hydrogen Tank: Simulation and Comparison with Experiments
}

\author{
Mark E. M. Stewart ${ }^{1}$ \\ VPL at NASA Glenn Research Center, Cleveland, Ohio, 44135, USA \\ Jeffrey P. Moder ${ }^{2}$ \\ NASA Glenn Research Center, Cleveland, Ohio, 44135, USA
}

\begin{abstract}
This paper presents ANSYS Fluent simulation results and analysis for self-pressurization of a flightweight, cryogenic, liquid hydrogen tank in 1-g. These results are compared with experimental data, in particular, pressure evolution and temperature measurements at a set of sensors. The simulations can be analyzed to identify and quantify heat flows in the tank. Heat flows change over time and influence the self-pressurization process. The initial rate of self-pressurization is sensitive to the initial temperature profile near the interface. Uncertainty in saturation pressure data and the accuracy of experimental measurements complicate simulation of self-pressurization. Numerical issues encountered, and their resolution, are also explained.
\end{abstract}

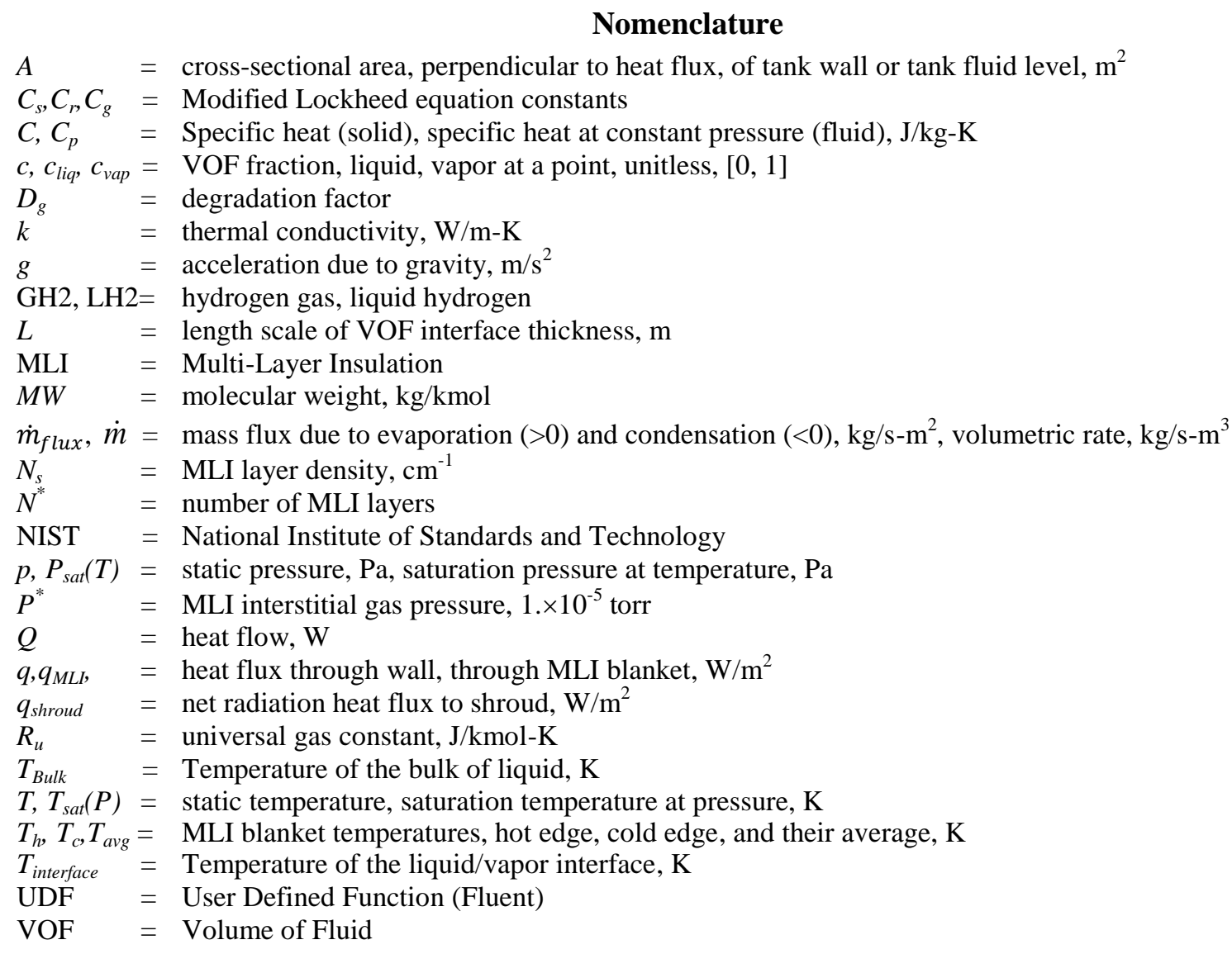

\footnotetext{
${ }^{1}$ Senior Research Engineer, MS VPL-3, AIAA Member.

${ }^{2}$ Monitor, Research Aerospace Engineer, Engine Combustion Branch, MS 5-10, AIAA Member.
} 
$Z=$ Compressibility factor, real gas molar volume to ideal gas molar volume, unitless

$\alpha \quad=$ underrelaxation parameter, unitless

$\varepsilon \quad=$ radiative emissivity, unitless

$\mu \quad=$ viscosity, $\mathrm{Pa} \mathrm{s}$

$\rho \quad=$ density, $\mathrm{kg} / \mathrm{m}^{3}$

$\sigma_{\text {cond }}, \sigma_{\text {evap }}=$ mass accommodation coefficients for condensation and evaporation, unitless

liq, vap, boil $=$ subscripts indicating liquid and vapor phases, and boiling conditions

\section{Introduction}

$\mathrm{N}$ ASA is interested in long-term, in-space storage of cryogenic propellants to support future exploration missions, including upper stages and potentially propellant depots. Cryogenic propellants promise higher specific impulse than storable hypergolic fuels, but storage for long duration missions must be demonstrated. Improving the capabilities of computational tools to predict fluid dynamic and thermodynamic behavior in cryogenic propellant tanks under settled and unsettled conditions is research supported under NASA's Evolvable Cryogenics project.

To test these simulation tools, the focus of this work is selfpressurization experiments performed in the early 1990's at NASA Lewis research center with a flightweight liquid hydrogen tank. The tank was tested at the heat fluxes, and conditions expected in future space exploration missions. The tank had high performance multilayer thermal insulation and a low mass-to-volume ratio. The intent of these original tests

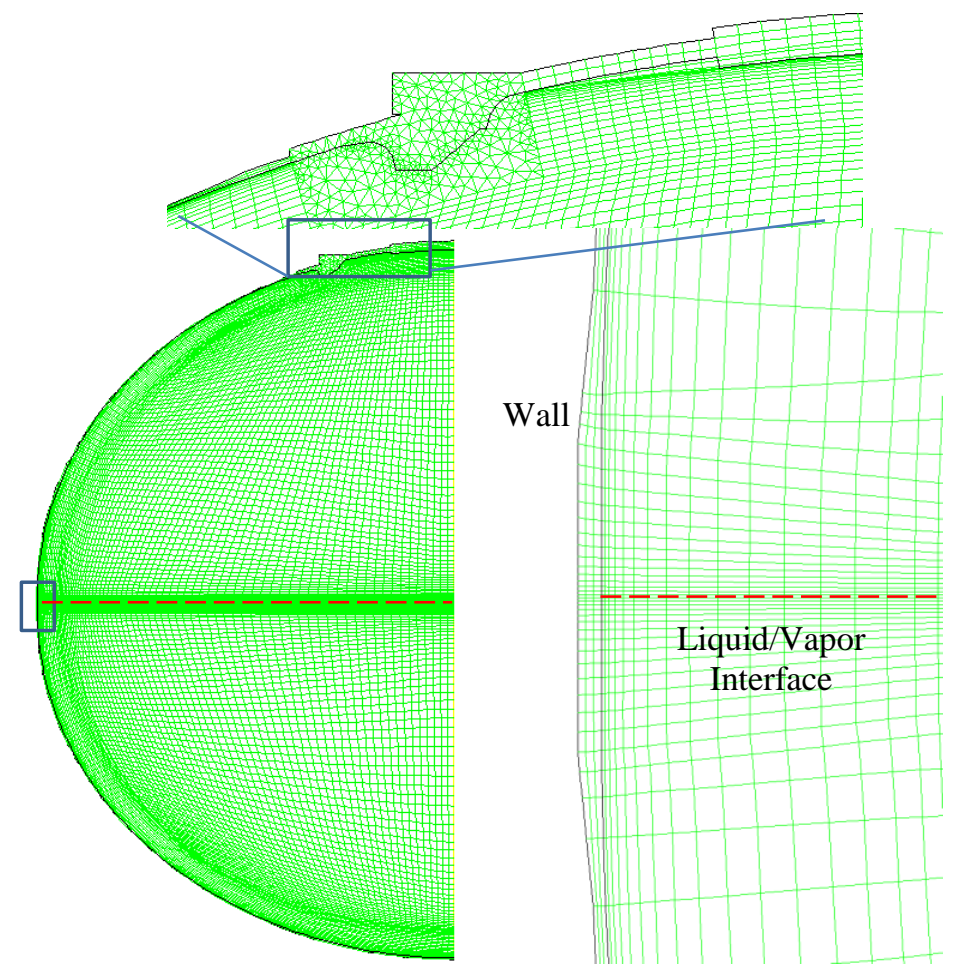

Figure 2: Cryogenic hydrogen tank grid (left), with inset (top) of unstructured grid for the lid, and inset (right) showing the grid where the tank wall meets the liquid/vapor interface. A thicker wall band with transition to thinner, chemically milled walls is also shown. The lid is treated as solid.

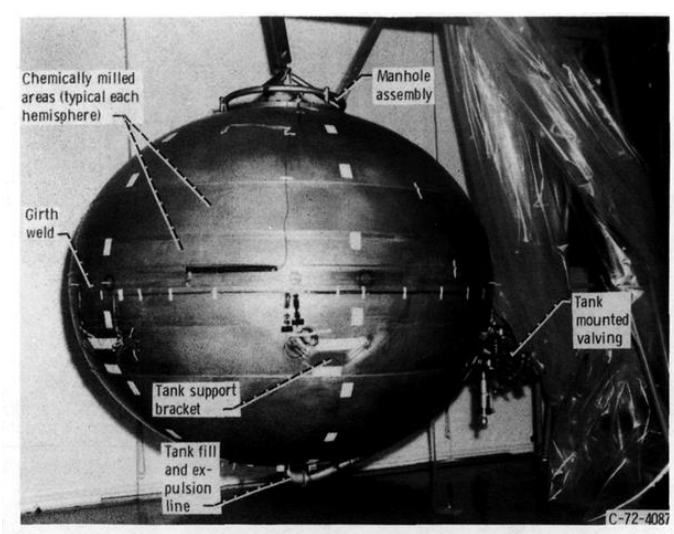

Figure 1: Cryogenic hydrogen tank without MLI insulation. From NASA TN D-8320.

was to understand the underlying physics of self-pressurization and predict design performance.

This paper is organized by topic and issue (sub-section) to cover the many issues in this complex simulation.

\section{Experimental Geometry and Grid}

The cryogenic hydrogen tank simulated is from the K-Site experiment (Figure 1) performed at the Cryogenic Propellant Tank Facility at NASA Plumbrook research center in the 1990's. This large, flightweight, 2219 aluminum tank with MLI insulation was tested in vacuum conditions [1] at $350 \mathrm{~K}$ shroud temperature and $1-\mathrm{g}$. The $2.2 \mathrm{~m}$ diameter tank consists of two elliptical domes and a very small barrel section. Although the tank was tested for self-pressurization at $29 \%, 49 \%$, and $83 \%$ fill levels, the current simulations are focused on the $49 \%$ fill level. MLI performance is documented in [2].

The computational domain is twodimensional, axisymmetric. The baseline grid contains 14,800 cells. A multi-block structured grid (Figure 2) captures variations in wall thickness: chemically milled wall sections (2 mm thick) (Figure 1), thicker wall bands (4.2 $\mathrm{mm}$ thick) where support struts are 
attached. Further, an unstructured grid represents the complex geometry of the lid of the manhole access. Some grids have a vent boundary condition to solve for the initial condition.

Solution accuracy is not simply proportional to the numerical scheme's order of accuracy, but also the local solution gradient; grid stretching has a role. Compared to the bulk fluid in the tank interior, this solution gradient is 1000 times greater near the walls (momentum and thermal boundary layers) and the interface (thermal layer). Consequently, the baseline grid has $0.5 \mathrm{~mm}$ normal spacing at the walls and $0.5 \mathrm{~mm}$ spacing at the liquid/vapor interface - 50 times more than the coarsest grid spacing in the bulk fluid region.

Coarser, similar, and finer grids were used to assess grid convergence (Table 3); however the finer grid is prohibitively expensive for long, time-dependent simulations.

\section{Material Properties and Numerical Methods}

ANSYS Fluent version 16.0 [3] is used to solve thermal equations in the solid walls coupled to thermal/fluid equations in the fluid region (two-dimensional, axisymmetric, Navier-Stokes equations). The simulation includes the VOF equations to capture two-phase flow, and the fluid flow is modeled as laminar flow. This transient simulation is second-order in space and time.

\section{A. Material Properties}

Constant fluid physical properties at reference conditions, $(20.354 \mathrm{~K}, 103.632 \mathrm{kPa})$, do not adequately capture thermal conductivity, $k$, in the gas phase and in the aluminum tank walls over the simulation's temperature range. Linear equations in temperature accurately represent NIST data [4] for viscosity, $\mu$, and thermal conductivity, $k$, of the gas phase hydrogen. NIST data [5] for 5083 aluminum is used for piecewise linear representations of the specific heat, $C$, and thermal conductivity, $k .5083$ aluminum data is indistinguishable from 2219 aluminum data [6] for thermal conductivity, and NIST data is publicly available and readily accessible on the internet [4] [5].

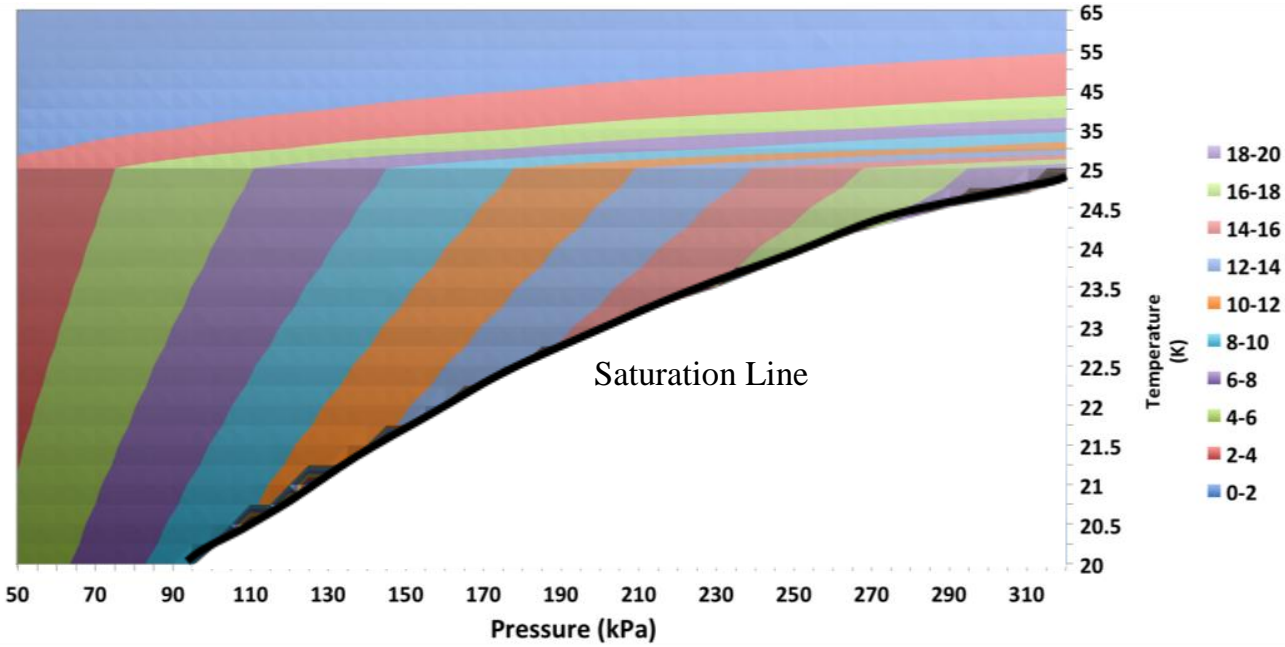

Figure 3: Percentage deviation of a real gas from ideal gas from NIST [4] hydrogen data: $(1-Z) * 100 \%$. Positive values indicate reduced volume. The black curve is the saturation line, $P_{\text {sat }}(T)$. Note the temperature scale change at $25 \mathrm{~K}$.

Hydrogen, a real gas, differs from an ideal gas by up to $12 \%$ over the temperatures and pressures in the simulation, as shown in Figure 3. The compressibility factor, $Z$, deviates most near the saturation line, at high pressures, and at low temperatures. In the simulations, the ideal gas assumption is used, so $Z$ is not corrected.

It is important to note that the ratio of thermal conductivities for $\mathrm{GH} 2: \mathrm{LH} 2: \mathrm{Al}$ is 1:6:1180 - the heat flux through the metal walls is much, much higher than in the vapor or liquid, and only partially mitigated by thin walls. Also, note that the volumetric heat capacity, $\rho C_{p}$, is as much as 40 times higher for LH2 than GH2, hence the liquid can absorb much more heat than vapor for the same temperature rise. Aluminum's volumetric heat capacity, $\rho C$, is similar to that of $\mathrm{GH} 2$.

\section{B.Saturation Conditions}

Why is the saturation line, $P_{\text {sat }}(T)$, and its representation so important? The self-pressurization experiment's vapor phase pressure evolution is the focus of this work. Vapor pressure is essentially constant in the gas phase at any time - perturbations travel everywhere at the speed of sound. Further, vapor pressure is not only the saturation pressure, $P_{\text {sat }}\left(T_{\text {interface }}\right)$, at the liquid/vapor interface, but it reflects the temperature of the interface, $T_{\text {interface }}$. Deviations from a single value of $T_{\text {interface }}$ - cold or hot, liquid or gas, impinging on the interface-results in 
evaporation in warm areas and condensation in cold areas that pushes the interface temperature to a single interface value - all mediated by the vapor pressure being held virtually constant at any time throughout the vapor phase. Hence, accurate saturation conditions are important if pressure evolution is to be captured.

Accurate representation of the saturation line is also important because saturation pressure is very sensitive to temperature-in fact, $\frac{d P}{d T}=\sim 30 \mathrm{kPa} / \mathrm{K}$ over the range of conditions studied here. Further, the accuracy of

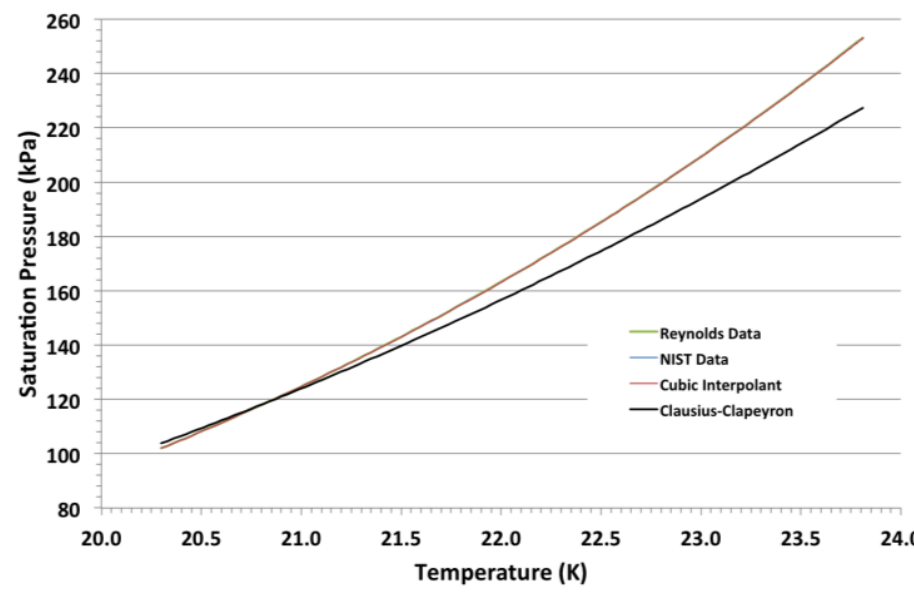

Figure 4: Saturation line, $P_{\text {sat }}(T)$, by NIST [4] and Reynolds [8] data for parahydrogen. Visually, the cubic interpolant lies on and obscures the NIST and Reynolds data. Uncertainty bars $( \pm 0.2 \%)$ are plotted for NIST data, but they are not visible on this scale. The Clausius-Clapeyron equation is not accurate over the temperature range.

three multiplications and three additions. Experimentally [1], the initial condition is $P_{\text {sat }}(20.354 \mathrm{~K})=103,632 \mathrm{kPa}$.

Fluent mentions the Clausius-Clapeyron equation [9, p. 608], and although it is accurate very close to one temperature, it is inappropriate for representing saturation pressure over large temperature ranges (Figure 4).

Clearly, the experimental temperature accuracy makes it difficult to match simulation results with experimental selfpressurization data.

\section{Mass Transfer: Evaporation and Condensation at the Interface}

The rate of mass transfer is calculated from the Schrage equation, Eq. (1), which is derived, in turn, from Maxwell's distribution. This evaporation/condensation internal boundary condition enforces saturation conditions at the liquid/vapor interface. Eq. (1) is implemented in a Fluent User-DefinedFunction (UDF) with the approximation $T_{l i q}=T_{v a p}, \sigma_{\text {evap }}=\sigma_{c o n d}$, and calculated every time step-but not every iteration. experimental liquid-vapor temperature measurements (silicon diode transducers) is \pm 0.1 $\mathrm{K}[1, \mathrm{p} .2]$, and wall temperatures are accurate to \pm 0.6 K. Consequently, the accuracy of temperature measurements lead to $\pm 3 \mathrm{kPa}$ accuracy of pressure measurement. Ref. [7] gives a good explanation of silicon diode temperature sensors, their calibration and operation.

The saturation line conditions for hydrogen, $P_{\text {sat }}(T)$, are represented by a cubic polynomial least squares fit to NIST data [4]; the interface temperature range is $[20.25,23.5] \mathrm{K}$, corresponding to gas phase pressures of 97.188 to $230.123 \mathrm{kPa}$, as shown in Figure 4. This polynomial fits NIST data to within $\pm 7 \mathrm{~Pa}$ across this temperature range which is less than the estimated uncertainty of $0.2 \%(\sim 200 \mathrm{~Pa})$. With Horner's rule, the cubic can be implemented with

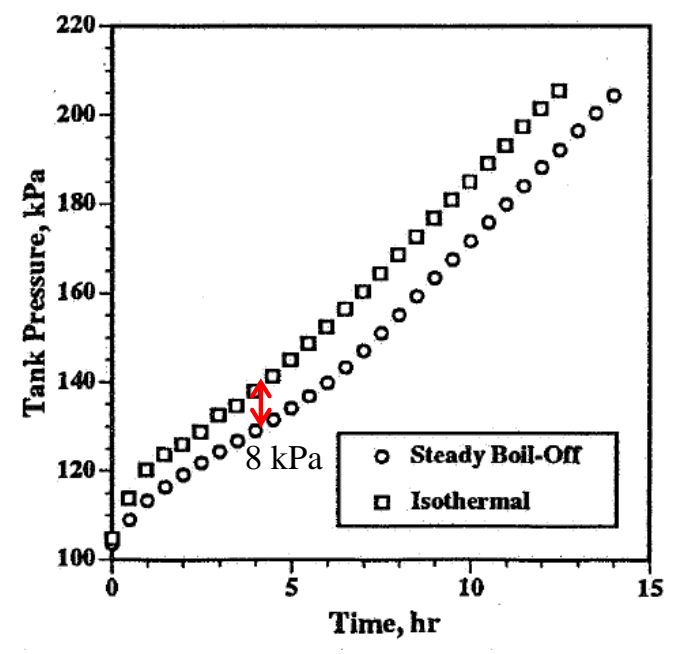

Figure 5: Experimentally observed effect of starting conditions on pressure rise rate. An $\sim 8 \mathrm{kPa}$ pressure difference develops in the first two hours. $q=3.5 \mathrm{~W} / \mathrm{m}^{2}$, Fill Level $83 \%$, From [1] and [22].

$$
\begin{gathered}
\dot{m}_{\text {flux }}=\frac{2}{2-\sigma_{\text {cond }}} \sqrt{\frac{M W_{\text {vap }}}{2 \pi R_{u}}}\left(\sigma_{\text {evap }} \frac{P_{\text {sat }}\left(T_{\text {liq }}\right)}{\sqrt{T_{\text {liq }}}}-\sigma_{\text {cond }} \frac{P_{\text {vap }}}{\sqrt{T_{\text {vap }}}}\right), \\
\dot{m}_{\text {net }}=\frac{\dot{m}_{\text {flux }}}{L} \quad \text { where } \quad L=1 /|\nabla c| \quad \text { converts flux to volumetric rate }
\end{gathered}
$$


The length scale of the VOF interface thickness, $L$, converts the flux to a mass transfer rate [10], Eq. (2). To smooth this value in time, it is underrelaxed every time step, $n, \quad \dot{m}_{\text {relax }}^{n}=\alpha \dot{m}_{n e t}^{n}+(1-\alpha) \dot{m}_{n e t}^{n-1}$, where the underrelaxation factor, $\alpha$, is typically 0.02 .

\section{Mass Accommodation Coefficients:}

Although there is evidence that mass accommodation coefficients are near 1 , here $\sigma_{\text {evap }}=\sigma_{\text {cond }}=0.001$ is used. An accommodation coefficient near 1 corresponds to a very fast mass transfer rate. We believe that another ratelimiting step exists in the process. In particular, heat flow through thin thermal boundary layers at the liquid/vapor interface limits the heat available for evaporation/condensation. Some mass transfer schemes are based on the interfacial heat flux [11]. The current simulations are not sensitive to the accommodation coefficient value, $\sigma$.

Classical molecular dynamics computer simulations of the air/water interface give mass and thermal accommodation coefficients of 0.99 and 1.0, respectively, at 300K [12]. Experimentally, the thermal accommodation coefficient was shown to be $0.84 \pm 0.05$ in argon at $271 \mathrm{~K}$ using sound resonance in a spherical chamber [13]. The experiment creates strong sound waves with a pressure oscillation both above and below saturation pressure - so evaporation and condensation alternate with the pressure wave; a liquid layer can exist on the walls but without a net heat flow [14].

\section{Unphysical Conditions and Loss of Fluid Mass:}

Condensation in an all liquid cell — or evaporation in an all vapor cell-must be avoided since it leads to a loss of fluid mass (see Section VI-A) when using Fluent's Define_Mass_Transfer() UDF. At every iteration and for every cell, Eq. (3) is applied. Multiplication by $c_{\text {liq }}$ or $c_{\text {vap }}$ ensures zero evaporation or condensation, respectively, in unphysical conditions, and this is Fluent's suggested approach [9, p. 608].

$$
\begin{array}{lll}
\text { if } \quad\left(\dot{m}_{\text {relax }}=0\right)\{\dot{m}=0\} & \\
\text { else if }\left(\dot{m}_{\text {relax }}>0\right)\left\{\dot{m}=\dot{m}_{\text {relax }} * c_{\text {liq }}\right\} & \text { Evaporation-liquid must be present } \\
\text { else if }\left(\dot{m}_{\text {relax }}<0\right)\left\{\dot{m}=\dot{m}_{\text {relax }} * c_{\text {vap }}\right\} & \text { Condensation-vapor must be present }
\end{array}
$$

Adding Eq. (3) to the mass transfer scheme avoids mass loss, but it may make convergence more difficult. For simulations that are otherwise identical, slightly shorter time steps have been required in simulations using Eq. (3).

\section{Heat Transfer Boundary Condition on the Tank Exterior Surface}

Heat transfer on the tank wall exterior surface is a boundary condition that includes heat leaks through MLI

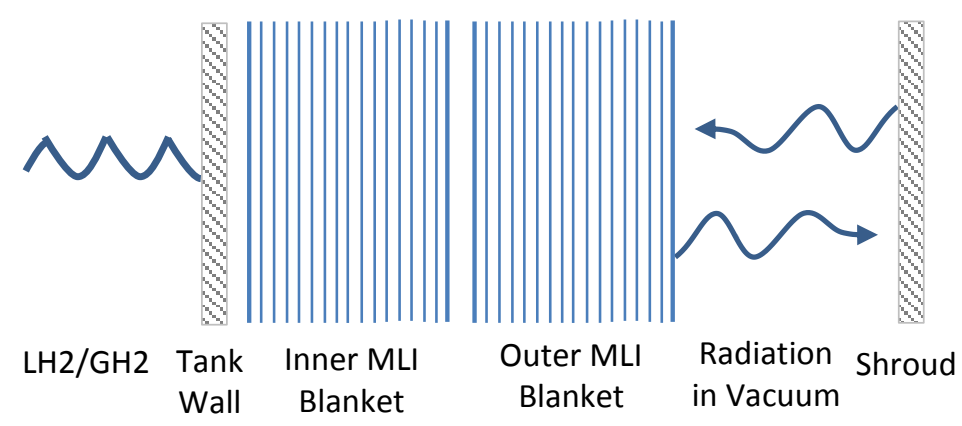

Figure 6: Architecture of MLI insulation layers. See [2, pp. 8-9]. Not to scale. insulation and through struts, plumbing and wires plus radiation to/from the shroud. The insulation consists of two MLI blankets each with 15 layers of double aluminized Mylar film (Figure 6) plus reinforced Mylar face sheets, with silk net spacers between these 17 layers. Table 1 gives the experimentally observed heat leaks where total heat flow is $48.2 \mathrm{~W}$. The heat leaks through struts, plumbing and wires are located on the wall, scaled to Table 1 values, and added to the MLI heat flux.

The local heat flux, $q_{M L I}$, through the

Table 1: Experimentally measured heat fluxes for $T_{\text {shroud }}=350 \mathrm{~K}, P^{*}=4.0 \mathrm{e}-6$ torr $[21, \mathrm{p} .8]$.

\begin{tabular}{|c|c|c|c|}
\hline Heat Leak Contributions & Heat Leak $(\mathbf{W})$ & \% Total Heat Leak & Heat Flux $\left(\mathbf{W} / \mathbf{m}^{\mathbf{2}}\right)$ \\
\hline 12 Struts & 2.813 & 5.83 & 0.201 \\
\hline Plumbing \& Ducts & 3.194 & 6.62 & 0.228 \\
\hline Wires & 0.879 & 1.82 & 0.063 \\
\hline MLI & 41.352 & 85.72 & 2.952 \\
\hline Total Heat Leaks & 48.239 & 100. & 3.444 \\
\hline
\end{tabular}


MLI insulation layers surrounding the tank is modeled with the Modified Lockheed equation [15], Eq. (4), and radiation exchange with the shroud, $q_{\text {shroud }}$, Eq. (5). These heat fluxes are calculated each time step for each cell and applied on the tank wall exterior surface as a thermal boundary condition. A Fluent UDF uses Eq. (4) and the local wall temperature to find the local heat flux, $q_{M L I}$, through each MLI blanket - but it must be the same through each blanket and equal to the external radiative heat flux, $q_{\text {shroud }}$, at each grid cell on the external wall. The algorithm [16] that enforces $q_{M L I}$ inner $=q_{M L I}$ outer $=q_{\text {shroud }}$ finds MLI blanket edge temperatures, $T_{h}$ and $T_{c}$, for equal heat flux through each blanket based on the local tank wall temperature, plus external radiation based on shroud temperature.

$$
\begin{gathered}
q_{M L I}=D_{g}\left[C_{S}\left(0.017+7 \times 10^{-6}\left(800-T_{\text {avg }}\right)+2.28 \times 10^{-2} \ln T_{\text {avg }}\right) N^{* 2.63}\left(T_{h}-T_{c}\right)+\right. \\
\left.C_{r} \varepsilon\left(T_{h}^{4.67}-T_{c}^{4.67}\right)+C_{g} P^{*}\left(T_{h}^{0.52}-T_{c}^{0.52}\right)\right] / N_{s}
\end{gathered}
$$

Table 2: MLI properties in two blankets [21].

\begin{tabular}{|r|c|c|c|}
\hline & MLI $_{\text {inner }}$ & MLI $_{\text {outer }}$ & Exterior \\
\hline MLI Layer Density, $N_{s},\left(\mathrm{~cm}^{-1}\right)$ & 17.7 & 17.7 & \\
\hline MLI Layers, $N^{*}$ & 17 & 17 & \\
\hline Emissivity, $\varepsilon$ & 0.04 & 0.04 & 0.05 \\
\hline Degradation factor, $D_{g}$ & \multicolumn{3}{|c|}{2.7216} \\
\hline Interstitial Gas Pressure, $P^{*},($ torr $)$ & \multicolumn{3}{|c|}{$1 . \times 10^{-5}$} \\
\hline Shroud Temperature, K & \multicolumn{3}{|c|}{350} \\
\hline Modified Lockheed & $C_{s}=2.4 \times 10^{-4} ; C_{r}=4.944 \times 10^{-10} ;$ \\
Equation constants & \multicolumn{3}{|c|}{$C_{g}=1.46 \times 10^{4}$} \\
\hline
\end{tabular}

$$
q_{\text {rad }}=\sigma \frac{T_{\text {Shroud }}^{4}-T_{M L I}^{4} \text { outer }}{\frac{1}{\varepsilon_{\text {Shroud }}+\frac{1}{\varepsilon_{\text {MLI outer }}}-1}}
$$

The degradation factor, $D_{g}$, is adjusted to match the overall heat flow, $48.2 \mathrm{~W}$. Results show (Figure 9) that total external wall heat flow is nearly constant throughout the simulations. The heat flux values for this tank wall boundary condition vary less than $5 \%$ over the entire surface, while wall temperature varies by $\sim 25 \mathrm{~K}$.

\section{E. Initial Conditions for K-Site Tank Simulations}

The original experimental report [1] noted that, "the starting conditions had a significant impact on the transient initial pressure rise rate." Two starting conditions, 'Steady Boil-Off' and 'Isothermal', were tested at the 29\% and $83 \%$ fill levels, but at the $49 \%$ fill level only Steady Boil-Off initial conditions were tested. Figure 5 shows the experimentally observed pressure difference between the two initial conditions for $83 \%$ fill — within the first hour, an $\sim 8 \mathrm{kPa}$ pressure difference develops between the two conditions; the pressure difference for $29 \%$ fill is similar [1].

How were these different starting conditions achieved experimentally? Paraphrasing Ref. [1], at the conclusion of the previous test, the tank was slowly drained to just above the desired fill level, and tank pressure was reduced to atmospheric pressure $(103 \mathrm{kPa})$. This venting "induces substantial bulk boiling of the fluid that initially produces nearly isothermal conditions in the tank." The Isothermal initial condition started from this condition, in particular,

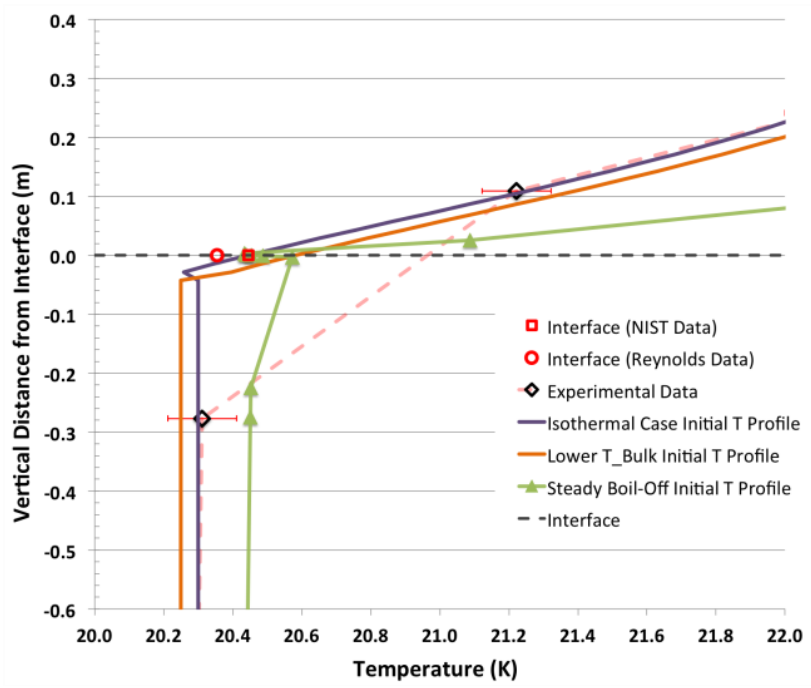

Figure 7: Initial temperature profiles for simulations. The initial pressure transient is very sensitive to the initial temperature profile near the interface. "shortly after tank pressure is reduced to atmospheric pressure by venting. As soon as the tank lid temperature reaches its minimum value $(\sim 23 \mathrm{~K})$, the test is begun by closing the vent line valves." For the Steady Boil-Off starting condition, tank venting was maintained for 4 hours or more until the liquid surface-to-tank lid temperature gradient and boil-off rate stabilized.

Boiling is a high heat transfer mechanismmuch higher than thermal conduction. Bulk boiling with vapor bubbles moving through the liquid would tend to create uniform liquid temperatures; vapor bubbles boiling at the wall and moving to the surface through colder fluid (below $T_{\text {sat }}(p)$ ) would contract as condensation heated the fluid while those moving through warmer fluid (above $T_{\text {sat }}(p)$ ) would expand as evaporation cooled the fluid.

What deviations from truly isothermal conditions might be expected in the Isothermal starting condition? With a pressure drop, evaporation will depress the fluid temperature near 
Table 3: Simulations, their grids, and initialization. Initial velocity zero. Experimentally measured temperature profile used for initialization in vapor phase and near the interface; bulk liquid temperature elsewhere.

\begin{tabular}{|l|c|c|c|c|c|c|c|}
\hline \multicolumn{1}{|c|}{ Case Name } & ID & Grid & Cells & $\begin{array}{c}\text { Time } \\
\text { Step } \\
(\mathbf{m s})\end{array}$ & $\begin{array}{c}\text { Interface } \\
\text { Normal } \\
\text { Spacing (mm) }\end{array}$ & $\begin{array}{c}\text { Wall Normal } \\
\text { Spacing } \\
(\mathbf{m m})\end{array}$ & $\begin{array}{c}\text { Initial Bulk } \\
\text { Liquid } \\
\text { Temperature (K) }\end{array}$ \\
\hline Isothermal-Fine & K8 & $4 \times$ Finer & 61,400 & 1 & 0.5 & 0.25 & 20.3 \\
\hline Isothermal & K10 & Baseline & 14,800 & 10 & 0.5 & 0.5 & 20.3 \\
\hline Steady Boil-Off & K12 & Improved Baseline & 15,100 & 10 & 0.5 & 0.5 & 20.3 \\
\hline Lower $\mathrm{T}_{\text {Bulk }}$ & O6 & $2 \times$ Coarser & 9,800 & 20 & 2.0 & 0.5 & 20.25 \\
\hline
\end{tabular}

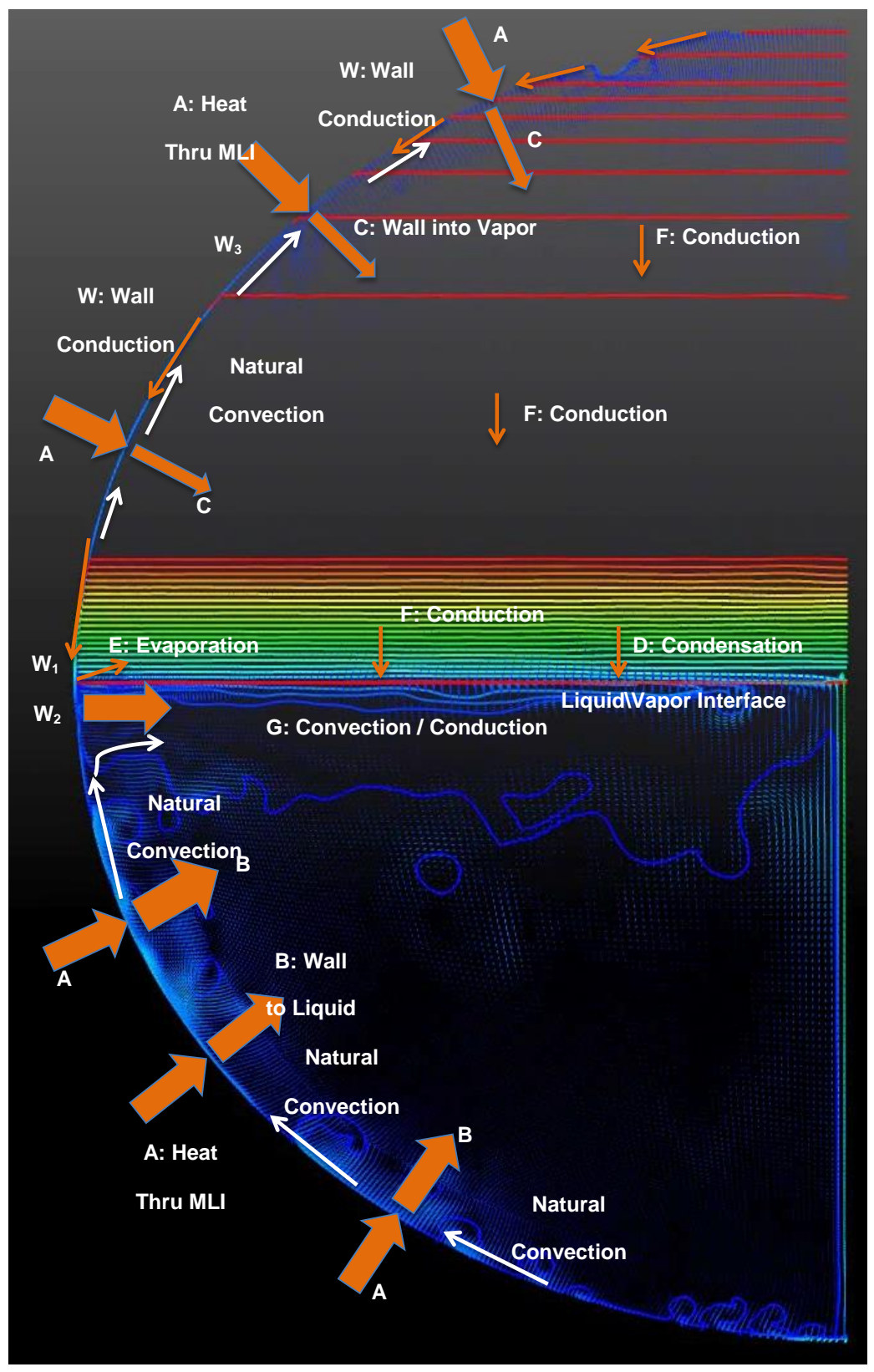

Figure 8: Isotherms help reveal heat flows in the K-Site tank simulation. Heat flows shown by orange arrows and fluid motion shown by white arrows. Heat pathways indicated by letters referenced to Figures 9 and 10. Heat flows change over time and reach equilibrium after $\mathrm{O}(10)$ hours. the interface as heat is consumed for evaporation. Typically, boiling requires a degree or two of superheating above saturation temperature, so boiling will end before true isothermal conditions are reached, and liquid near the walls will be above $T_{\text {sat }}(p)$. A smaller effect is pressure head. For the $49 \%$ fill LH2 case, the pressure at the tank bottom is $650 \mathrm{~Pa}$ higher than the interface, corresponding to a saturation temperature $0.022 \mathrm{~K}$ warmer. Certainly, isothermal conditions only hold approximately. Further, from available experimental data [17], there is only data for one temperature sensor in the bulk liquid. Its initial value is $20.256 \mathrm{~K}$ and it remains below 20.354 $\mathrm{K}$ for over an hour.

Numerical simulations indicate that the initial pressure transient (Figure 5) is very sensitive to the initial temperature profile near the interface (Figure 7). The Isothermal case was initialized with the initial temperature profile from experimental data [17] in the vapor phase and near the interface, plus $T_{\text {liq }}=20.3 \mathrm{~K}$ (Figure 7) in the bulk liquid. The Lower $\mathrm{T}_{\text {Bulk }}$ case changes only $T_{\text {liq }}=20.25 \mathrm{~K}$. To simulate starting conditions, the Steady BoilOff simulation was run with several hours of venting at $p=103.632 \mathrm{kPa}$ before self-pressurization, so $T_{\text {interface }}=$ $T_{\text {sat }}(p=103.632 \mathrm{kPa})=20.354 \mathrm{~K}$. But note the complex profile in Figure 7 with temperature depressed at the interface.

\section{F. Simulation Operational Details: Starting Simulations and} Monitoring Time Step Convergence

Baseline and fine grid simulations are hard to start even from good initial 
conditions; coarse grids are more forgiving. Initial iterations at small time steps will start these grids: 300 iterations at $10^{-5} \mathrm{~s}, 300$ at $10^{-4} \mathrm{~s}, 3000$ at $10^{-3} \mathrm{~s}, 3000$ at $2 \times 10^{-3} \mathrm{~s}, 3000$ at $4 \times 10^{-3} \mathrm{~s}$.

The interface temperature must be close to saturation conditions, $T_{\text {sat }}\left(p_{\text {initial }}\right)$, or the simulation will start with large amounts of evaporation or condensation as the solution moves the interface to saturation conditions; solutions may not tolerate this shock.

To detect potential problems, solutions are monitored for global mass conservation, and global total energy conservation. It is easy to miss convergence at a time step since it is buried in Fluent's output. An awk script scans output to detect sporadic, malignant convergence failure in individual time steps. During the simulation, longer time steps are tested to see if they are possible while maintaining convergence. Table 3 gives the highest time steps used.

\section{Results: Observed Phenomena and Behavior}

The original self-pressurization experiment report noted that "the mode of heat transfer is complex and is the greatest factor controlling the pressure rise rate.” [1, p. 9]. The simulations have been analyzed to identify and

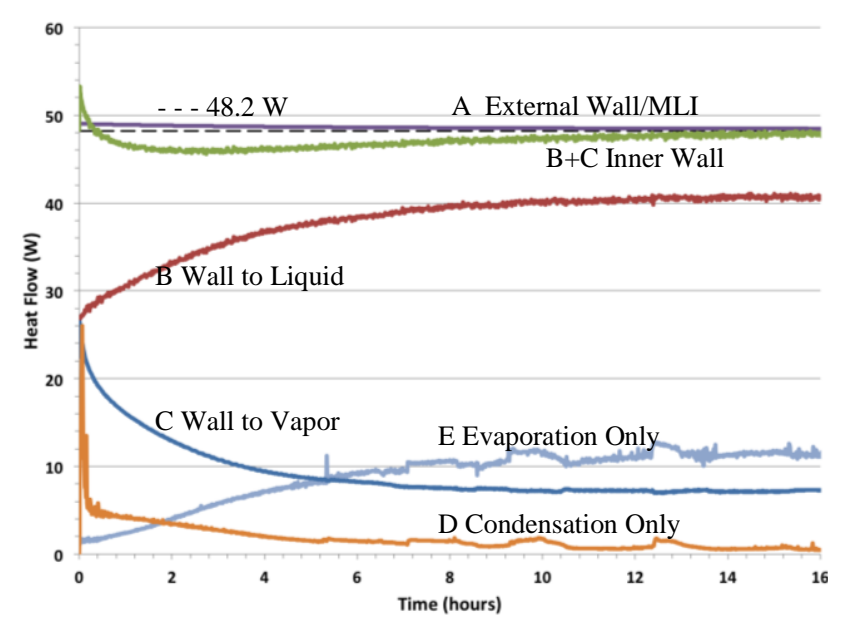

Figure 9: Global heat flows within the tank simulation with time. Heat flows are identified by letter, corresponding to flows in Figure 8. Isothermal case.

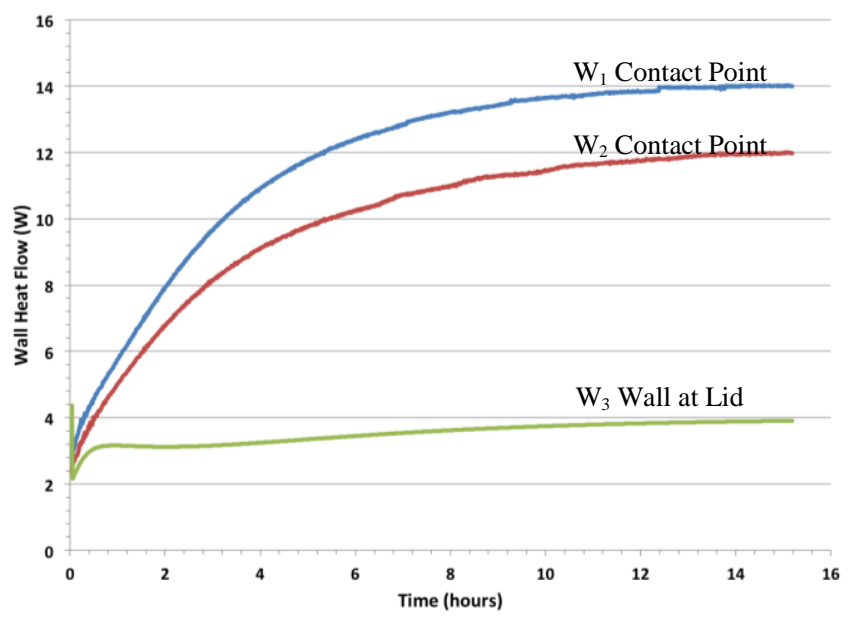

Figure 10: Heat flow tangential to the wall as measured by various pairs of temperature sensors. The aluminum walls are very conductive: the ratio of thermal conductivities for GH2:LH2:Al is 1:6:1180. Letters correspond to Figure 8. Isothermal case. quantify heat transfer mechanisms as well as fluid behavior.

\section{A. Heat Transfer Paths}

Figure 8 shows the heat transfer paths identified in the simulations. Important paths include heat transfer through the MLI (denoted A), substantial heat conduction tangentially through the thin-yet highly conductive - tank walls (denoted $\mathrm{W}_{1}, \mathrm{~W}_{2}$, $\mathrm{W}_{3}$ ), much more heat transfer from the wall into the liquid than the vapor $(\mathrm{B}, \mathrm{C})$, natural convection along the tank walls, and condensation (D) and evaporation (E) at the liquid/vapor interface. Smaller heat flows include conduction (F) through the vapor phase towards the interface, and convection, turbulent conduction (G) through the liquid phase towards the interface.

Figures 9 and 10 show measurements of these heat flows over time marked with letters. Importantly, these heat flow rates change with time, and only reach equilibrium after $\mathrm{O}(10)$ hours.

There is so much heat flow through the walls into the liquid, as noted above, because aluminum has relatively high thermal conductivity. Also, the LH2 can absorb much more heat than $\mathrm{GH} 2$ for the same temperature rise.

\section{Measuring Heat Flows}

How do we quantify and calculate these heat flows? The Fluent solution includes boundary heat fluxes that are integrated over the wall inner and outer surfaces (heat flows A, B, C) every 100 time steps. For condensation and evaporation (denoted $\mathrm{D}, \mathrm{E})$, mass transfer is integrated over the volume.

Temperatures at specific locations are logged through the simulation and used to estimate the conductive heat flow, Eq. (6), and how it changes through the simulation.

$$
Q=k \frac{T_{2}-T_{1}}{x_{2}-x_{1}} A
$$




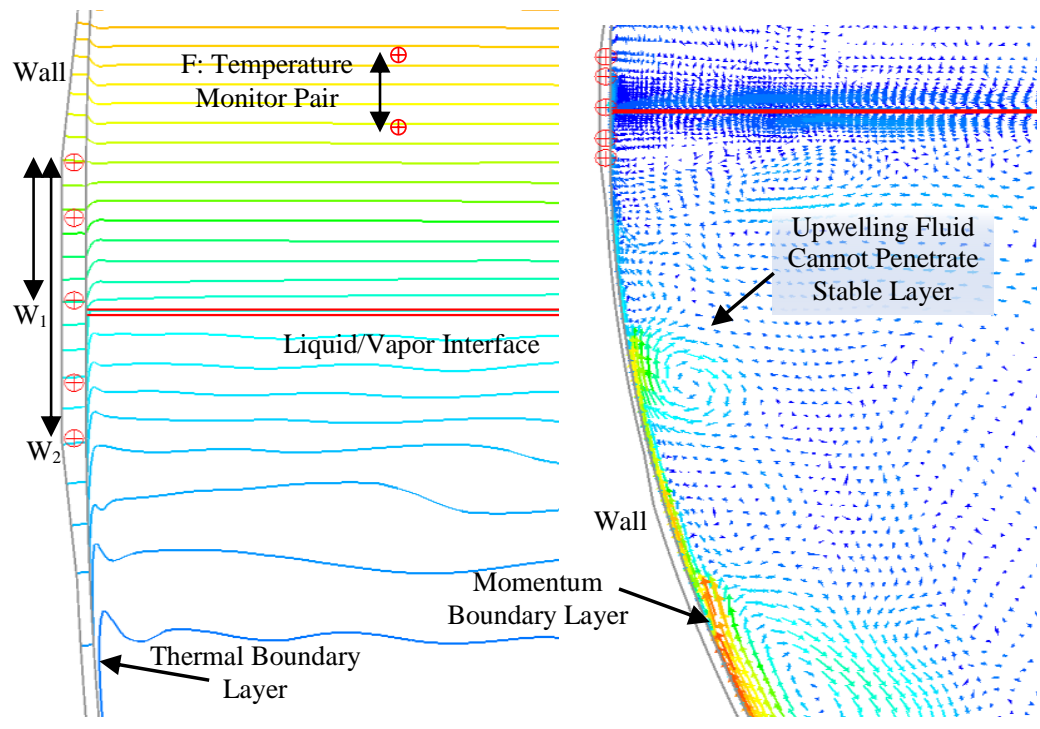

Figure 11: Temperature contours $(\Delta T=0.05 \mathrm{~K})$ (left) near the contact point and (right) velocity vectors in the surrounding region. Red cross circles indicate temperature monitor locations for calculating heat flux and estimating heat flow. The temperature monitor pairs $\mathrm{W}_{1}$ and $\mathrm{W}_{2}$ are used to calculate heat flow through the wall near the contact point. The $\mathrm{F}$ temperature pair calculates vapor conductive heat flow. $\mathrm{K} 8$ simulation at $2000 \mathrm{~s}$, velocity color range $[0,0.25] \mathrm{m} / \mathrm{s}$.

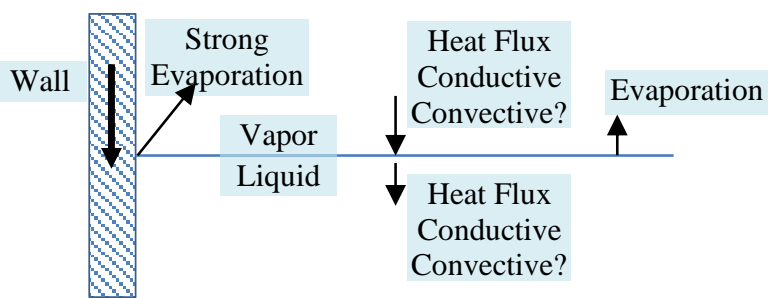

Figure 12: Heat Flows at the interface.

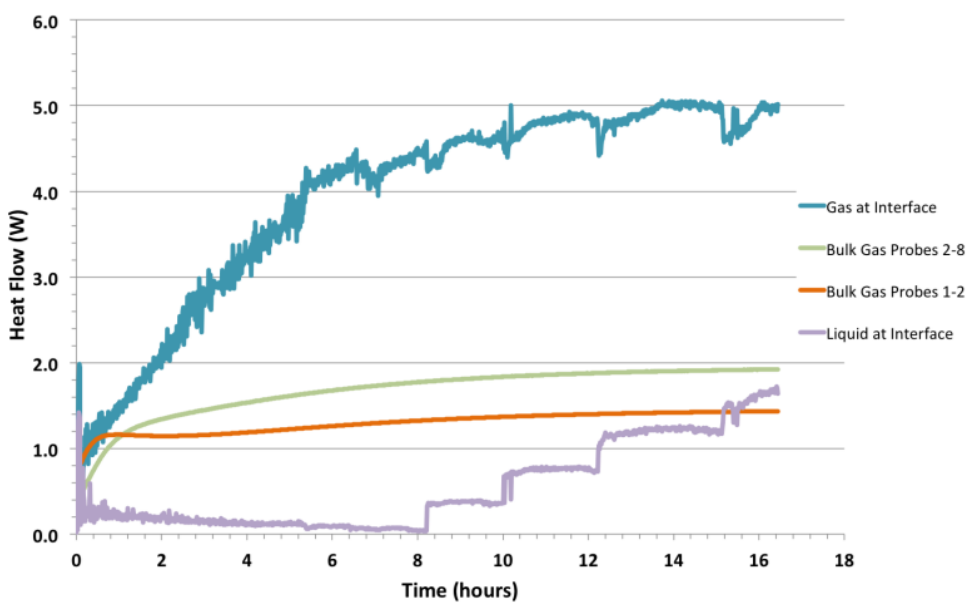

Figure 13: Estimated heat flows at and near the interface. A rake of five temperature monitors in the simulation provides estimates of heat flow using Eq. (6). Note that a point value of heat flux is extrapolated to the entire interface. Heat flow is vertically downwards. Bulk gas monitors 1, 2, 8 suggest similar values.
For example, heat flow tangential to the wall near the contact point (denoted $\mathrm{W}_{1}, \mathrm{~W}_{2}$ ) is calculated from the temperature monitor pairs shown in Figure 11 -plus an estimate of the wall cross-sectional area, $A$. Note that a point estimate of heat flux is extrapolated to a heat flow for an area, A.

Heat conduction in the vapor phase is measured with Eq. (6) and many pairs of temperature monitors, like those shown in Figure 11. From many measurements, the typical vapor phase heat flow is $1.5-3.5 \mathrm{~W}$ at a fluid level-small for such a large fluid level area. A separate simulation (Steady Boil-Off) on a similar size/resolution grid gives similar heat flux values.

\section{B. Pressure Evolution, Interface Temperature, and Heat Fluxes into the Interface}

Vapor pressure is not only the saturation pressure, $P_{\text {sat }}\left(T_{\text {interface }}\right)$, at the liquid/vapor interface, but it reflects an average temperature of the interface, $T_{\text {interface }}$. Deviations from a single value of $T_{\text {interface }}$ - cold or hot, liquid or gas, impinging on the interface-results in evaporation in warm areas and condensation in cold areas that pushes the interface temperature towards a single interface value.

Further, heat fluxes into the interface supply or remove the heat energy required for evaporation or condensation - influencing pressure evolution. Figure 12

demonstrates interfacial heat flows conceptually, and Figure 13 gives interfacial heat flow estimates from a rake of five temperature monitors spanning 1 $\mathrm{cm}$ of the interface, using Eq. (6) and extrapolated to the entire interface. After an initial transient, the vapor to interface conductive heat flow reaches a value of 5 $\mathrm{W}$ into the interface. Convective heat flow is hard to measure, and could be small. Many temperature monitor pairs in the gas suggest similar gas phase heat fluxes.

Similarly, the interface to liquid conductive heat flow is small. Convective heat transfer is more likely here. Most evaporation occurs near where the meniscus meets the wall. 


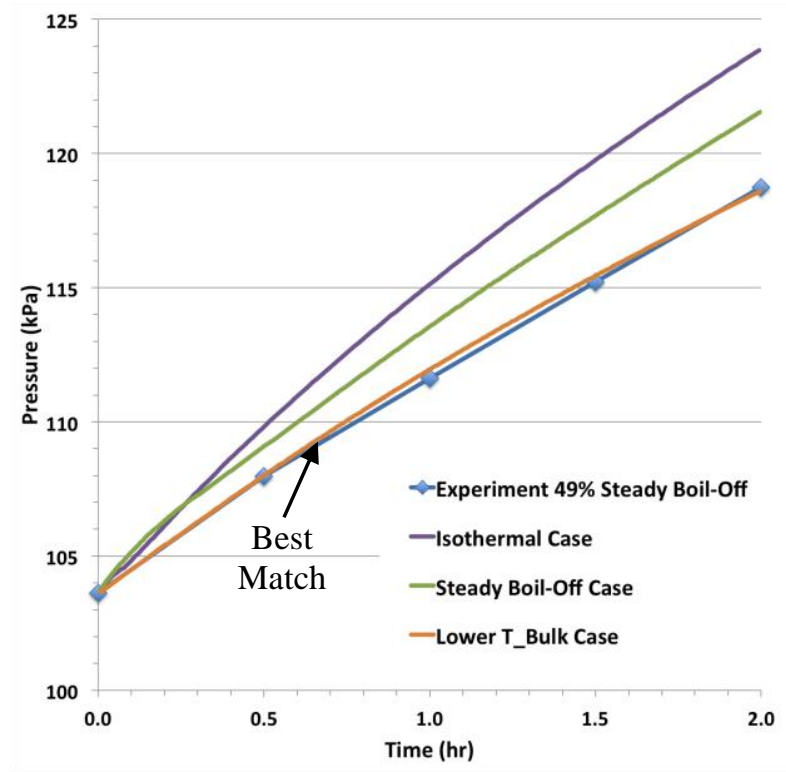

Figure 14: Initial pressure evolution in experiments and simulations. The Lower $\mathrm{T}_{\text {Bulk }}$ case at $49 \%$ fill matches experimental data best; it uses an $0.05 \mathrm{~K}$ lower bulk liquid temperature, which, presumably, reduces heat conduction from liquid to the interface, and slows interface temperature increase. The closeness of the match is much less relevant than the demonstrated temperature sensitivity. Experimental pressure accuracy $\pm 0.01 \mathrm{kPa}$.

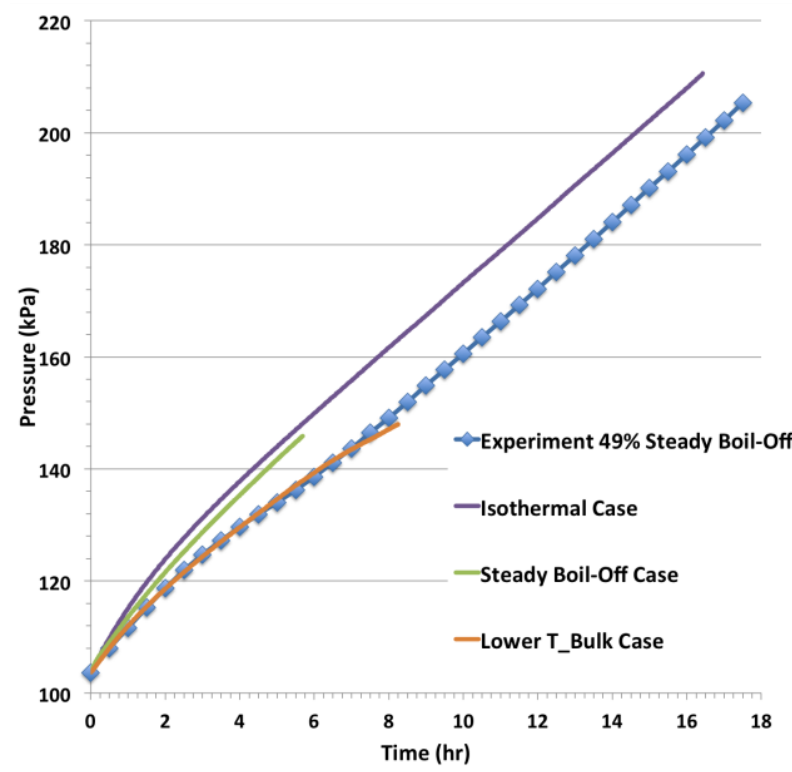

Figure 15: Pressure evolution during experiment and simulations. The Isothermal case at $49 \%$ fill displays the pressure evolution that would be expected for Isothermal initial conditions, but no experimental data exists for comparison. The Lower $\mathrm{T}_{\text {Bulk }}$ case closely matches the Steady Boil-Off experimental conditions at $49 \%$ fill level until 8 hours when it under predicts pressure. The Lower $\mathrm{T}_{\text {Bulk }}$ case uses a $0.05 \mathrm{~K}$ lower bulk liquid temperature (Figure 7).

\section{Natural Convection Up the Walls}

Figure 8 shows that buoyantly driven flow (natural convection) occurs in the liquid along the wall, and to a lesser extent in the vapor near the wall. Heat transfer from the wall to the liquid creates a thin thermal boundary layer of warm liquid that is buoyantly driven up the wall. This velocity creates a thin momentum boundary layer (Figure 11). The buoyantly driven liquid accumulates in a stable layer of warm liquid near the interface. Eventually, this layer is warm and thick enough to buoyantly decelerate the upwelling flow along the wall, and the flow cannot penetrate the layer. Figure 11 demonstrates this buoyancy barrier in contrast to Figure 18 where the barrier has not formed early in the simulation. This phenomena contributes to the complex heat transfer process.

\section{Less Relevant Phenomena and Behavior}

\section{Internal Gravity Waves}

Obviously, the interface can have waves if it is perturbed, but internal gravity waves would also occur within the density stratified vapor and liquid phases. These waves are observed numerically at very short time steps. Internal gravity waves should not significantly influence mixing unless the waves break. Breaking near the rim of the manhole access is likely. Similarly, wave breaking around instrumentation rakes is likely.

\section{Results and Comparison with Experimental Data}

\section{A. Initial Pressure Evolution}

As noted in Section III-E, the initial pressure evolution is very sensitive to initial conditions: Isothermal and Steady Boil-Off. Figure 5 shows a pressure difference of $\sim 8 \mathrm{kPa}$ develops over the first two hours in the $83 \%$ fill case for the two different initial conditions. The $29 \%$ fill case is similar.

Several initial temperature profiles (Figure 7) were tested in simulations for the $49 \%$ fill level, and Figure 14 shows three results. The Steady Boil-Off case tried to initialize with several hours of evaporative venting, but with only a modest improvement. Yet, the best agreement with experimental data is in the Lower $\mathrm{T}_{\text {Bulk }}$ case (Table 3 ), where a $0.05 \mathrm{~K}$ lower bulk liquid temperature was used-20.25 K instead of $20.3 \mathrm{~K}$. From available experimental data [17], there is only one temperature sensor in the bulk liquid, with an initial value of $20.256 \mathrm{~K}$. Of course, all these temperature differences are well within the experimental temperature sensor accuracy range.

How do we interpret this behavior? The initial pressure rise, $\mathrm{P}_{\text {sat }}\left(\mathrm{T}_{\text {interface }}\right)$, reflects the temperature rise of the interface and the local heat flows that determine it. A 10 


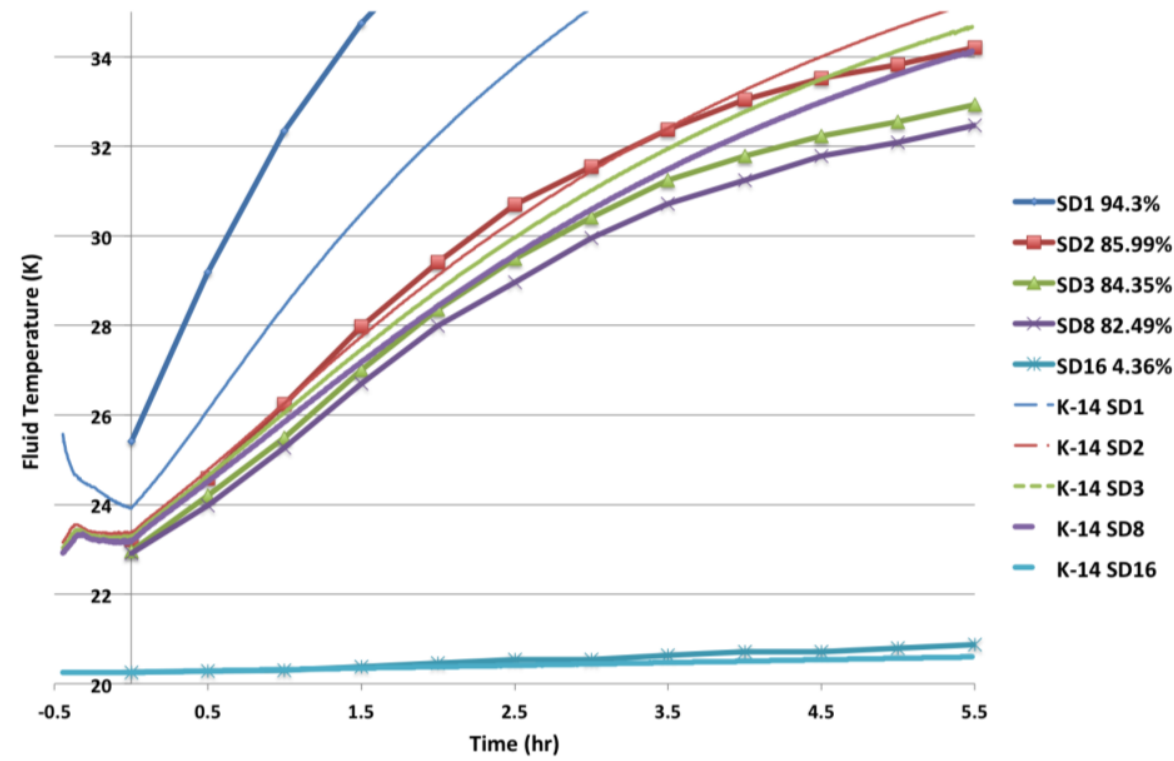

Figure 16: Comparison of temperature evolution at five experimental and simulated fluid sensors. The Steady Boil-Off case shows good agreement except at the top sensor in the lid. The tank lid is simulated as a solid piece neglecting the reduced thermal contact conductance at the bolted joint. The simulation temperatures for negative time are solving venting conditions for the initial conditions. Experimental temperature sensors calibrated to $\pm 0.1 \mathrm{~K}$.

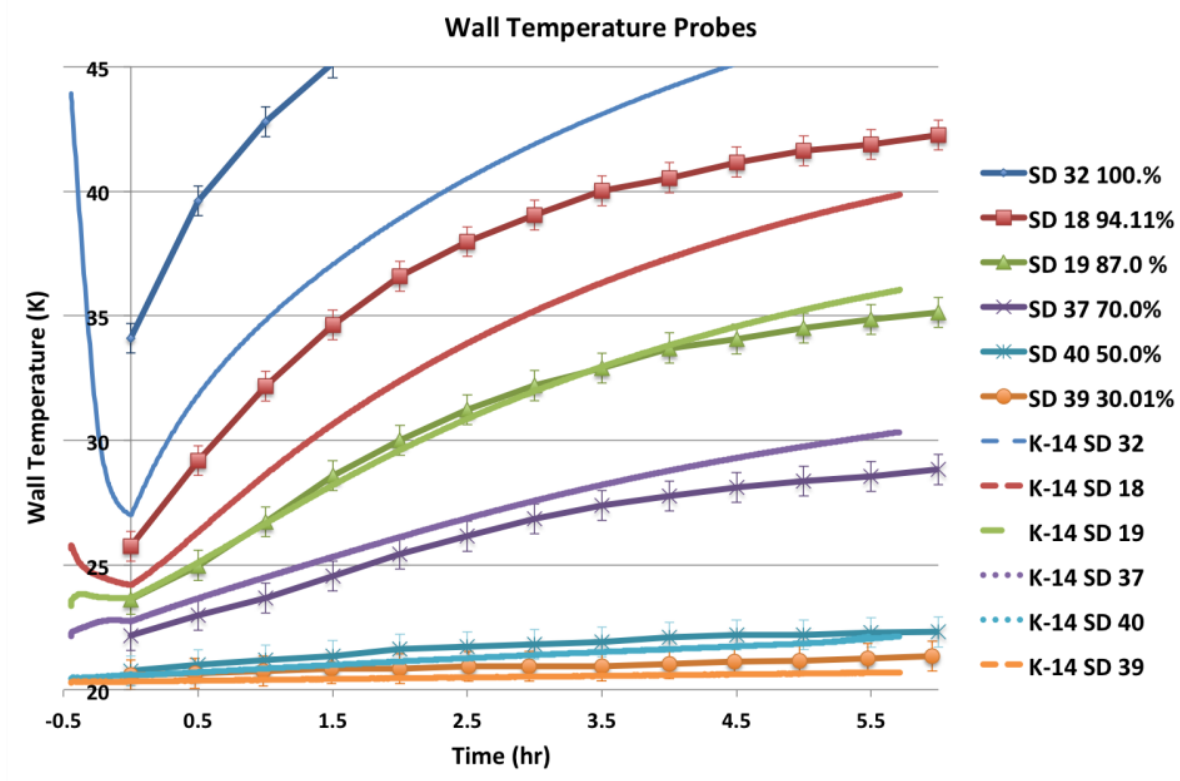

Figure 17: Comparison of temperature evolution at six experimental and simulated wall sensors. The Steady Boil-Off case shows good agreement except for sensors near the tank top and lid. The tank lid is simulated as a solid piece neglecting the reduced thermal contact conductance at the bolted joint. The simulation temperatures for negative time are solving venting conditions for the initial conditions. Experimental temperature sensors calibrated to $\pm 0.6 \mathrm{~K}$ lower bulk fluid temperature reduces the heat flow to the interface and slows the interface temperature rise.

In conclusion, the closeness of the match between experimental and Lower $\mathrm{T}_{\text {Bulk }}$ case data is much less relevant than the demonstrated temperature sensitivity.

\section{B. Pressure Evolution}

Figure 15 compares the pressure evolution during the experiment with two computational results. The available experimental data [1] [17] at $49 \%$ fill is for Steady Boil-Off initial conditions. The Lower $\mathrm{T}_{\text {Bulk }}$ case agrees with experimental results up to 8 hours when it under predicts the pressure rise. This case uses a $0.05 \mathrm{~K}$ lower bulk liquid temperature.

The Isothermal case data display the behavior that would be expected for Isothermal initial conditions, but no experimental data exists for comparison.

\section{Fluid and Wall Temperature Evolution}

The agreement between experimental and simulation fluid and wall temperature sensors is good except near the tank lid and top as shown in Figure 16 and Figure 17. This difference is attributed to treating the man access lid (Figure 2) as a solid piece of aluminum and neglecting the reduced thermal contact conductance of the bolted joint. Studies of heat transfer through bolted joints indicate reduced heat transfer [18]. This issue should be corrected in a future simulation of the $\mathrm{K}$ Site tank. 


\section{Numerical Observations}

In performing these simulations, several numerical subtleties were observed that deserve mention as they improved these simulations and are important for future simulations.

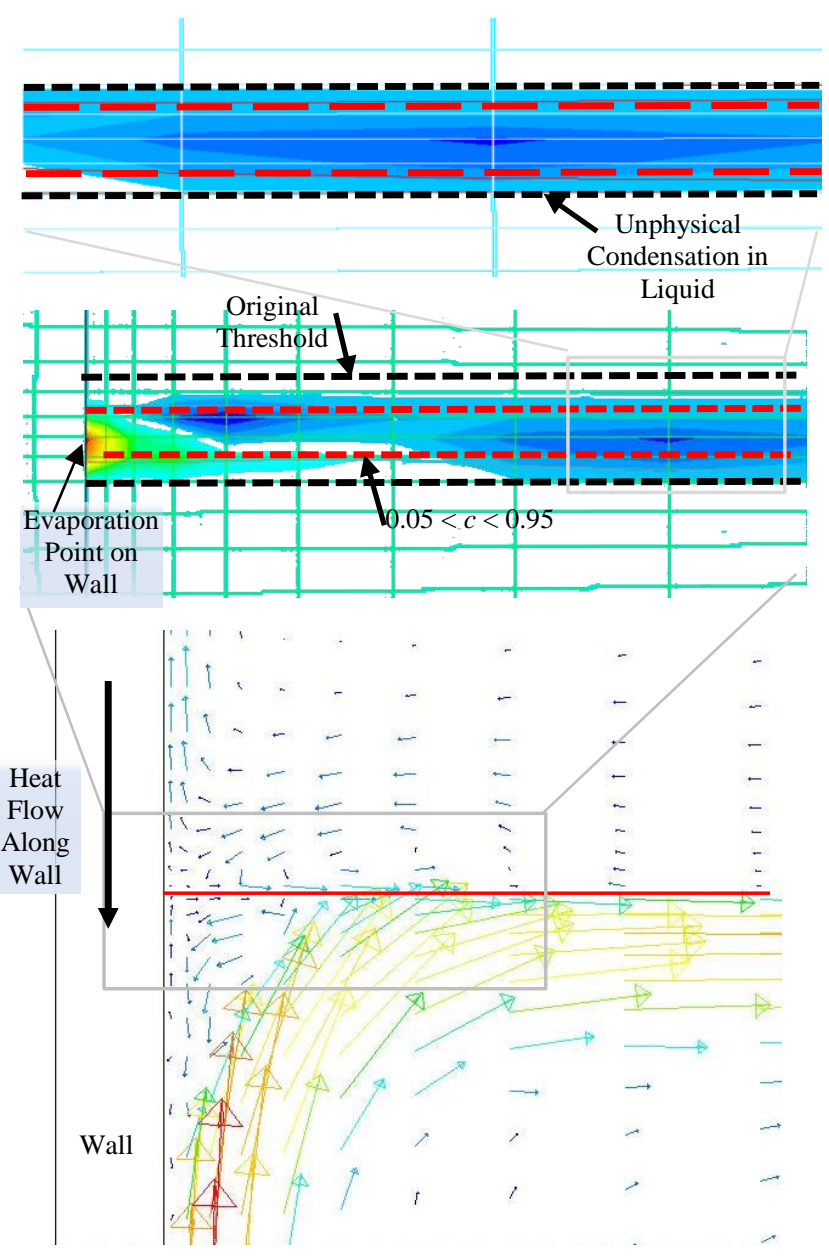

Figure 18: Interface region near the contact point showing velocity vectors (below) with inset for (middle) $\mathbf{P}_{\text {sat }}-\mathbf{P}$ plus thresholds (original in black; $0.05<c<0.95$ in red) for calculating mass transfer with inset for detail (top). Unphysically specifying condensation in liquid filled cells resulted in mass loss.

\section{A. Mass Loss in the Simulations and Its Resolution}

Early K-Site tank simulations showed a slow fluid mass loss of $\sim 500$ grams over several hours, corresponding to an interface level drop of several millimeters. This mass loss was traced to the mass transfer UDF, Fluent's Define_Mass_Transfer(), and which grid cells included mass transfer, $\dot{m}$. If mass transfer was allowed where $0.05<c<0.95$ - between the red interface boundaries in Figure 18-then mass was conserved $10^{3}$ times better than in the traditional region-between the black boundaries. The interpretation is that an unphysical condition exists when condensation is specified in a cell containing all liquid and no vapor. Further, Fluent's mass transfer implementation assumes physical consistency, and the Theory Manual $[9$, p. 608] shows one way to filter out these inconsistencies. Eq. (3) excludes condensation in liquid filled cells and evaporation in vapor filled cells.

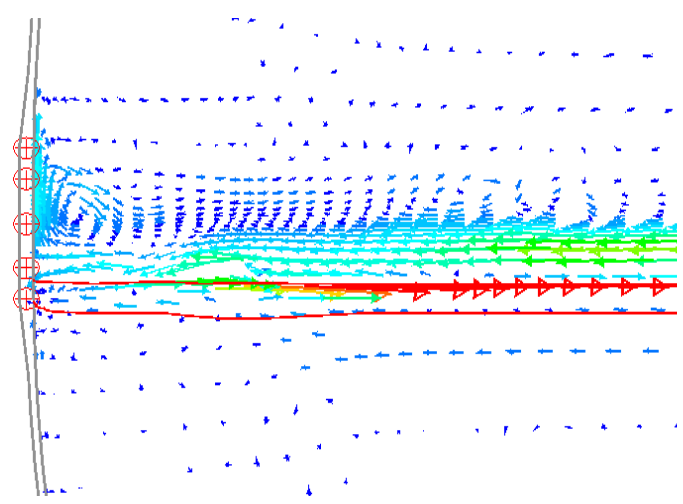

Figure 19: Spurious velocity vectors along the liquid/vapor interface (red lines) - 'Where does this momentum come from?' Surface tension modeling with VOF results in these spurious velocities. From $\mathrm{K} 5$ simulation at $17820 \mathrm{~s}$; velocity range [0, 0.157] $\mathrm{m} / \mathrm{s}$.

\section{B. Surface Tension Modeling}

Initial simulations found spurious velocities along the liquid/vapor interface as shown in Figure 19. The operative question was: Where is this momentum coming from? This issue was traced to surface tension modeling, which the literature [19] indicates is a known issue with VOF. Surface tension modeling was not included in subsequent simulations, and the behavior of the interface was much more plausible as shown in Figure 11 and Figure 18. Since including surface tension would only resolve the meniscus $(\sim 2 \mathrm{~mm}$ high $)$ at the contact pointwhich is poorly resolved by the grids anyway - this is an appropriate modeling choice here.

\section{Evaporation at the Meniscus/Contact Point}

Another phenomena contributing to the complexity of this simulation is evaporation at the meniscus where the liquid/vapor interface meets the wall. As measured in Figure 10 and demonstrated in Figure 18, there is a 
substantial heat flow $(10-15 \mathrm{~W})$ through the aluminum wall at the contact point. Further, simulations show a point of strong evaporation on the wall at the contact point as shown in Figure 18 and Figure 20.

Where can the heat in the wall go? Above the contact point, heat transfer is limited by conduction into a very

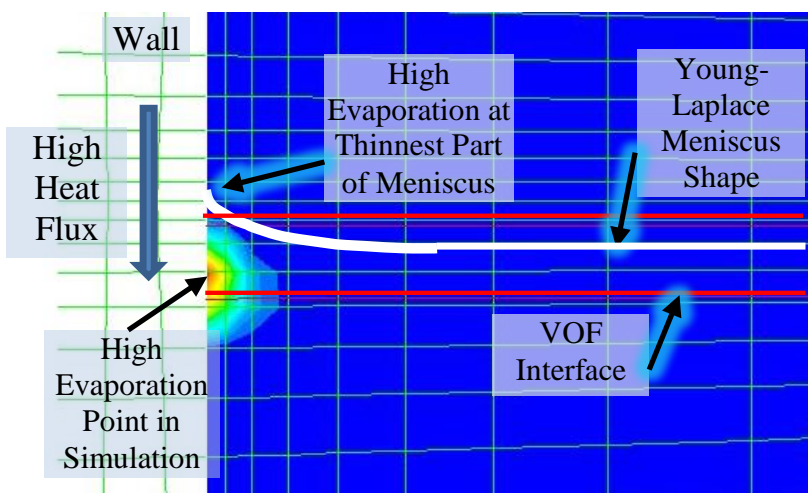

Figure 20: Comparison of VOF interface and actual meniscus shape. The meniscus height is $\sim 2$ $\mathrm{mm}$ for contact angles less than 10 degrees. There is a point of high evaporation in the simulation, and high evaporation is expected at the thinnest point in the meniscus. Both points are enabled by high heat flux through the wall. non-conductive gas- $\mathrm{GH} 2$ is 1180 times less conductive than aluminum. Similarly, below the contact point, heat transfer is limited by heat conduction into a non-conductive liquid-LH2 is 200 times less conductive than aluminum. Yet evaporative heat transfer is possible in between at the thinnest part of the meniscus: the wall heats the liquid on one side of the film, and it evaporates on the other. The liquid's thermal conductivity doesn't slow heat transfer when the meniscus is so thin. Independent models indicate substantial heat flow and evaporation in the thinnest art of the meniscus. Some experiments have been done with a sub-grid model for this additional evaporation source.

Solutions to the Young-Laplace equations [20] indicate a meniscus height of $\sim 2 \mathrm{~mm}$ for contact angles less than 10 degrees-3-4 grid cells on the baseline Isothermal grid as shown in Figure 20. Despite the highest resolution of the grid, the simulation may not resolve this evaporation.

\section{Conclusion}

This paper documents the successful implementation of detailed tank geometry and MLI insulation into a cryogenic hydrogen tank simulation. Self-pressurization has been carefully studied and simulated. In particular, heat flows within the tank have been identified and quantified based on multiple simulations. Further, the sensitivity of the initial pressure rise to the initial temperature profile near the interface has been identified. Numerical issues have been identified and remedied, and they will improve future cryogenic fluid simulations. These issues include surface tension modeling, improved representation of saturation pressure, and identification and repair of mass loss in the simulation. Clearly, both experimental measurement accuracy and uncertainty in saturation pressure, $\mathrm{P}_{\text {sat }}(\mathrm{T})$, complicate simulation of pressure evolution. Better calibration of experimental temperature sensors would be helpful, particularly at the interface and in the LH2. That velocity variations are introduced at the interface is a concern for the VOF method. Real gas effects should be accounted for in future simulations. Thermal contact conductance at bolted joints should also be included.

\section{Acknowledgments}

The authors thank Olga Kartuzova, Jason Hartwig, Mojib Hasan, Mohammed Kassemi, Sonya Hylton, Barbara Sakowski, and Matt Melis for helpful discussions. Matt Melis supported this work in the NASA Space Technology Mission Directorate's Technology Demonstration Missions Program under the Evolvable Cryogenics Project.

\section{References}

[1] N. T. Van Dresar, C. S. Lin and M. M. Hasan, "Self-Pressurization of a Flightweight Liquid Hydrogen Tank: Effects of Fill Level at Low Wall Heat Flux," NASA TM 105411 and AIAA 92-0818, Reno, NV, January 1992.

[2] R. L. DeWitt and R. J. Boyle, "Thermal Performance of an Integrated Thermal Protection System for LongTerm Storage of Cryogenic Propellants in Space," NASA TN D-8320, Washington, May 1977.

[3] ANSYS, ANSYS Fluent User's Guide, Release 14.0, Canonsburg, PA: ANSYS, Inc., 2011.

[4] NIST, "Thermophysical Properties of Fluid Systems," National Institute for Standards and Technology, 2011. [Online]. Available: http://webbook.nist.gov/chemistry/fluid. [Accessed January 2015].

[5] NIST, "Material Measurement Laboratory: Cryogenics Technologies Group," [Online]. Available: 
http://cryogenics.nist.gov/MPropsMAY/materialproperties.htm. [Accessed 2015 April].

[6] T. H. Squire, F. S. Milos and D. J. Rasky, "TPSX: Thermal Protection System Expert and Material Property Database," in Fourth International Conference on Composites Engineering, Moffett Field, Jan 1997.

[7] S. S. Courts, P. R. Swinehart and C. J. Yeager, "A New Cryogenic Diode Thermometer," [Online]. Available: http://www.lakeshore.com/Documents/DT-670\%20Overview.pdf. [Accessed 13 May 2016].

[8] W. C. Reynolds, Thermodynamic Properties in SI: graphs, tables and computational equations for 40 substances, Dept. of Mech Eng, Stanford University, 1979.

[9] ANSYS, ANSYS Fluent Theory Guide, Release 14.0, Canonsburg, PA: Ansys, Inc., Nov 2011.

[10] O. Kartuzova and M. Kassemi, "Modeling Interfacial Turbulent Heat Transfer during Ventless Pressurization of a Large Scale Cryogenic Storage Tank in Microgravity," in AIAA, 2011.

[11] Y. Umemura, T. Himeno and K. Kinefuchi, "Numerical Modeling of Boiling Flow in a Cryogenic Propulsion System," in 51 st AIAA/SAE/ASEE Joint Propulsion Conference, Orlando, FL, July 2015.

[12] J. Vieceli, M. Roeselova and D. J. Tobias, "Accommodation coefficients for water vapor at the air/water interface," Chemical Physics Letters, vol. 393, pp. 249-255, 2004.

[13] M. B. Ewing, M. L. McGlashan and J. P. M. Trusler, "The Temperature-Jump Effect and the Theory of the Thermal Boundary Layer for a Spherical Resonator. Speeds of Sounds in Argon at 271.16K," Metrologia, vol. 22, pp. 93-102, 1986.

[14] J. B. Mehl and M. R. Moldover, "Precondensation phenomena in acoustic measurements," J. Chem. Phys., vol. 77, no. 1, pp. 455-465, July 1982.

[15] C. W. Keller, G. R. Cunnington and A. P. Glassford, "Thermal Performance of Multi-Layer Insulations," Lockheed Missiles \& Space Company, Final Report, Contract NAS3-14377, 1974.

[16] L. J. Hastings, A. Hedayat and T. M. Brown, "Analytical Modeling and Test Correlation of Variable Density Multilayer Insulation for Cryogenic Storage," NASA TM-2004-213175, Huntsville, May 2004.

[17] Private Communication.

[18] A. K. J. Hasselsström and N. U. Eskil, "Thermal Contact Conductance in Bolted Joints," Dept of Materials and Manufacturing Technology, Chalmers University of Technology, Gothenburg, 2012.

[19] D. J. E. Harvie, M. R. Davidson and M. Rudman, "An analysis of parasitic current generation in volume of fluid simulations," ANZIAM J., vol. 46, no. (E), pp. C133-149, 2005.

[20] G. K. Batchelor, An Introduction to Fluid Dynamics, p. 66-67: Cambridge University Press, 1967.

[21] R. J. Stochl and R. H. Knoll, "Thermal Performance of a Liquid Hydrogen Tank Multilayer Insulation System at Warm Boundary Temperatures of 630, 530, and 152 R," NASA TM 104476, Cleveland, 1991.

[22] M. M. Hasan, C. S. Lin and N. T. Van Dresar, "Self-Pressurization of a Flightweight Liquid Hydrogen Storage Tank Subjected to Low Heat Flux," NASA TM 103804, 1991. 